Article

\title{
Fractional Order Chaos Synchronization for Real-Time Intelligent Diagnosis of Islanding in Solar Power Grid Systems
}

\author{
Cheng-Biao Fu ${ }^{1}$, An-Hong Tian ${ }^{1}$, Yu-Chung $\mathrm{Li}^{2}{ }^{2}$ and Her-Terng Yau ${ }^{3, *}$ \\ 1 College of Information Engineering, Qujing Normal University, Qujing 655011, China; \\ fucb@mail.qjnu.edu.cn (C.-B.F.); tianah@mail.qjnu.edu.cn (A.-H.T.) \\ 2 Department of Mechanical Engineering, National Cheng Kung University, 1 University Road, \\ Tainan City 701, Taiwan; a238966777@gmail.com \\ 3 Department of Electrical Engineering, National Chin-Yi University of Technology, Taichung 41170, Taiwan \\ * Correspondence: pan1012@ms52.hinet.net or htyau@ncut.edu.tw; Tel.: +886-4-23924505
}

Received: 9 April 2018; Accepted: 7 May 2018; Published: 8 May 2018

\begin{abstract}
Many different methods have been proposed for determining islanding and most of them have drawbacks. The main issue is the difficulty of detecting islanding when the current and voltage values are of the same phase or the frequency remains within the normal range of the grid when islanding occurs. In this study, a non-autonomous Chua's circuit was used to preprocess the grid signal after which a method based on the fractional Lorenz chaotic system and extension theory was used to analyze the preprocessed voltage signal. The capability of a chaotic system to amplify an extremely small signal was effectively utilized for the diagnosis of grid islanding. Simulation results showed that the diagnostic accuracy of the proposed method could be $100 \%$ and no other diagnostic method has offered such accuracy. Furthermore, the method proposed in this study is simple, easy to implement, and could be used as a portable system for the real-time monitoring and diagnosis of islanding in a conventional home grid system.
\end{abstract}

Keywords: Chua's circuit; islanding; fractional Lorenz chaotic system; extension theory

\section{Introduction}

Grid-connected solar power systems [1,2] have now become main stream [3]. The structure is simple, easy to maintain, and can effectively increase the power grid peak backup capacity [4], but protection against islanding is needed. The term islanding refers to a situation that can arise should the solar generation system continue to power the load when the main grid has been interrupted for some reason. During an islanding event, workers making repairs may be in serious danger and the equipment and even the power generation system itself might sustain damage. The detection of islanding can be active or passive. Passive detection involves monitoring the voltage, frequency, and phase at the load end and the data is analyzed to determine islanding. Active detection involves perturbation of the voltage or frequency in such a way that when islanding occurs, the resulting disturbance causes a clear variation in the system, which can then be used to determine if islanding exists. Several relatively simple diagnostic methods have been devised. Some of those presently in use include the power changing rate detection $[5,6]$, the voltage harmonic detection $[5,6]$, and the phase jump detection methods $[5,6]$. These are all simple and easy to implement. However, when the output of the solar power generation system and load consumption are close to being in balance, these methods all become less effective. Consequently, there is a need for a better way to detect islanding.

Recently, many methods have become available and new intelligent algorithms have been developed, which improve detection accuracy and efficiency. Among these is a method for islanding 
detection based on new active disturbance [7] and one for active movement frequency anti-islanding detection [8]. Even though these methods can reduce the time taken to detect islanding, they can also affect the stability of the system or even lead to overall harmonic distortion. Furthermore, if the operating area (for islanding detection) includes other relatively stable power sources connected in parallel such as cogeneration systems. These methods will fail. New algorithms such as the Neural Network Algorithm (NNA) [9] have also been used in detecting islanding. Even though the neural network learns fast, it has a free mode and error tolerance and allows the use of reverse transmission direction to modify the weight and make corrections after repetition. It has a complicated training process that takes a long time. Accurate determinations cannot be made with other algorithms such as Fuzzy Theory [10] or the Genetic Algorithm (GA) [11] when the voltage, frequency, and phase differences are small. The Goertzel Algorithm [12], which is a Discrete Fourier Transformation (DFT) [13], has been recommended in some studies, but the conversion time is long and the width of the Fourier conversion window is fixed. This means that, when the time domain requires high resolution, the harmonic resolution will drop and the method is less than optimal. In 2015, a new, very accurate method has been proposed by Wang et al., which uses the Lorenz integer order [14] to detect islanding. However, many nonlinear systems exhibit fractional-order behavior. Therefore, if the fractional-order concept is considered in the diagnosis system, more accuracy can be obtained with a real physical system. In this study, the use of a non-autonomous Chua's circuit [14] for preliminary processing of the grid signal is described. This is followed by fractional Lorenz chaotic synchronization [15] and the product element model characteristics of the self-synchronization dynamic error are then analyzed. Afterward, the extension method is used to detect the occurrence of islanding. The Chua's circuit is simple, uses few components, and is easy to connect. Chaotic synchronization detection and extension allows for fast calculation and the method is expected to reduce the time for retrieving the waveform characteristics as well as computation time. Chaos is a nonlinear solution type. Therefore, the chaotic system has an advantage of sensitivity for the initial condition and the small change of system parameters. The chaotic system has been applied to many fields such as the design of a controller to avoid or keep chaos motion in the system [16-18] and even the design of a controller to synchronize between different fractional order chaotic systems [19].

When voltages value from the normal state to the islanding state, the chaotic system will be a good method for identifying and diagnosing the islanding state in this study. The system can be realized easily as a chip and, when compared to the integral Lorenz chaotic system [20], its dynamic error values are seen to be more suitable for analysis because the method reduces detection time and includes real-time monitoring while maintaining detection accuracy.

\section{The Islanding Effect}

According to a report from the Sandia National Laboratory in the USA [21], Islanding arises when the main power company supply is interrupted by malfunction or as a result of direct action taken for maintenance. The individual solar power generation systems connected to the grid cannot readily detect the power outage situation and may remain connected to the grid power network. In such a case, the solar power generation system continues to supply power to the grid. This provides self-sustained power to the load [22], which is outside the control of the power company. This can lead to voltage, phase, and frequency disturbances. The phenomenon is termed islanding [23] and is illustrated in the photovoltaic power generation system and the grid-connected network diagram in Figure 1. IEEE 1547, IEC 61727, and NEC 690 have detailed specifications of power system distribution and grid-connected networks. The need for detecting and preventing islanding is growing because grid-connected power supply systems are now becoming much more common. When islanding does occur, it can put workers in serious jeopardy as well as cause damage to the equipment. 


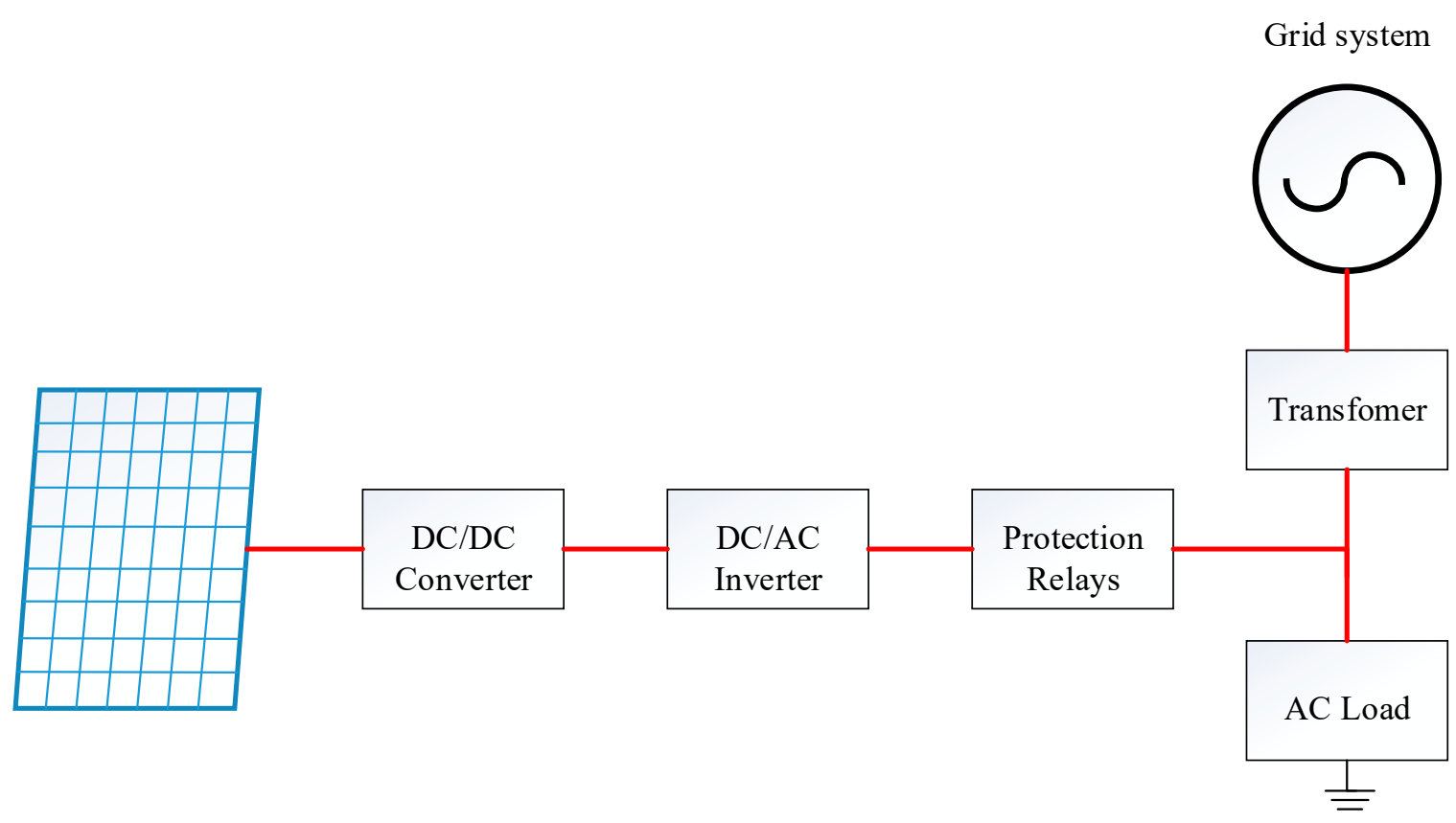

Figure 1. Photovoltaic power generation system and grid-connected network.

The current methods used to prevent islanding [14] include Voltage Harmonic Detection, Phase Jump Detection, and Power Change Rate Detection. However, a nonlinear load, incorrect impedance matching, or an unbalanced load can cause these methods to malfunction.

\section{The CHUA's Circuit}

The simple layout of Chua's Circuit [14] designed by Chua in 1983 is shown in Figure 2. The circuit has three active components, capacitors, inductors, and resistors including a nonlinear resistor $\mathrm{R}_{\mathrm{L}}$.

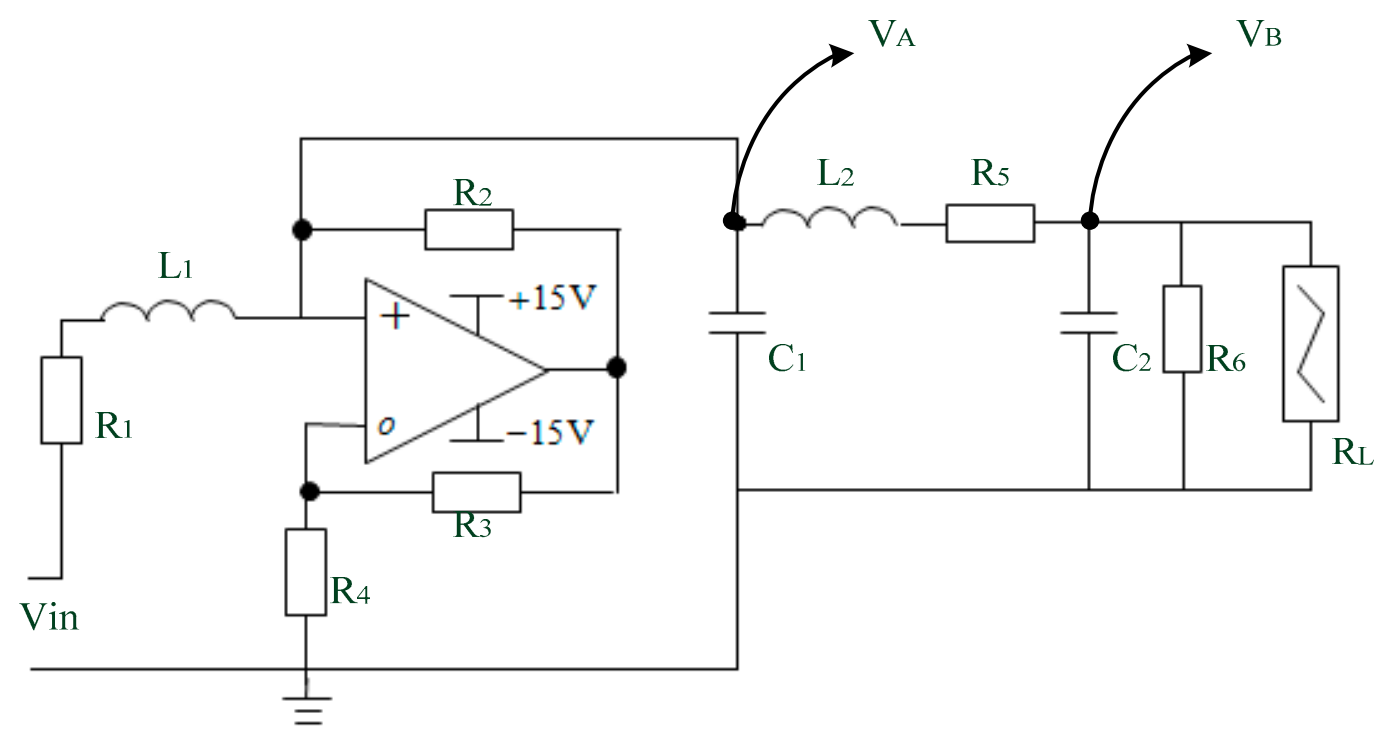

Figure 2. Diagram of the Chua's circuit. 
According to the Kirchhoff Circuit Laws, the state of the Chua's circuit can be obtained from Equation (1).

$$
\left\{\begin{array}{l}
C_{1} \frac{d V_{C 1}}{d t}=-g V_{C 1}+i_{L 1}-i_{L 2} \\
C_{2} \frac{d V_{C 2}}{d t}=i_{L 1}-i_{R L} \\
L_{1} \frac{d i_{L 1}}{d t}=-V_{C 1}-i_{L 1} R_{1}+V_{i n} \sin (2 \pi k) \\
L_{2} \frac{d i_{L 2}}{d t}=V_{C 1}+V_{C 2}+i_{L 2} R_{5}
\end{array}\right\}
$$

where $\mathrm{k}$ refers to the high-level harmonic correspondence parameter. $i_{L R}$ is defined in Equation (2).

$$
i_{L R}=G_{a} V_{c 2}+\frac{1}{2}\left(G_{b}-G_{a}\right)\left[\left|V_{c 2}+E_{a}\right|-\left|V_{c 2}-E_{a}\right|\right]
$$

where $G_{a}$ and $G_{b}$ are slopes and $E_{a}$ is a breakpoint.

In this study, the grid voltage was input to a non-autonomous Chua's circuit followed by capture of the $V_{A}$ and $V_{B}$ waveforms as characteristics (see Figure 3). The extension element model was formed after a fractional chaotic self-synchronization dynamic error conversion on the voltage waveform, which had been carried out. Finally, the extension algorithm was used to determine the presence or absence of islanding. Figure 4 is a diagram showing the grid-connected network with Chua's circuit.

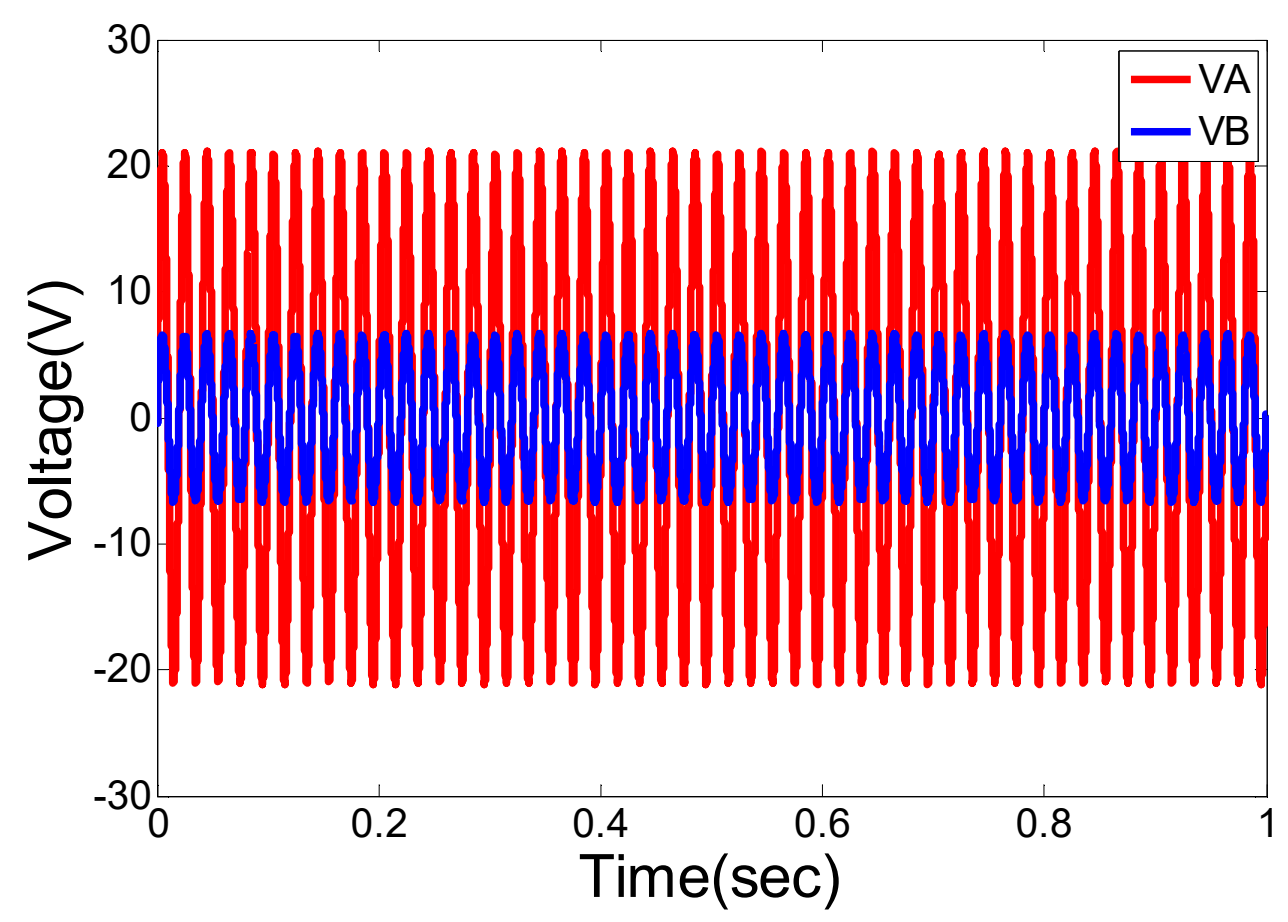

Figure 3. $V_{A}$ and $V_{B}$ voltage waveform graph. 


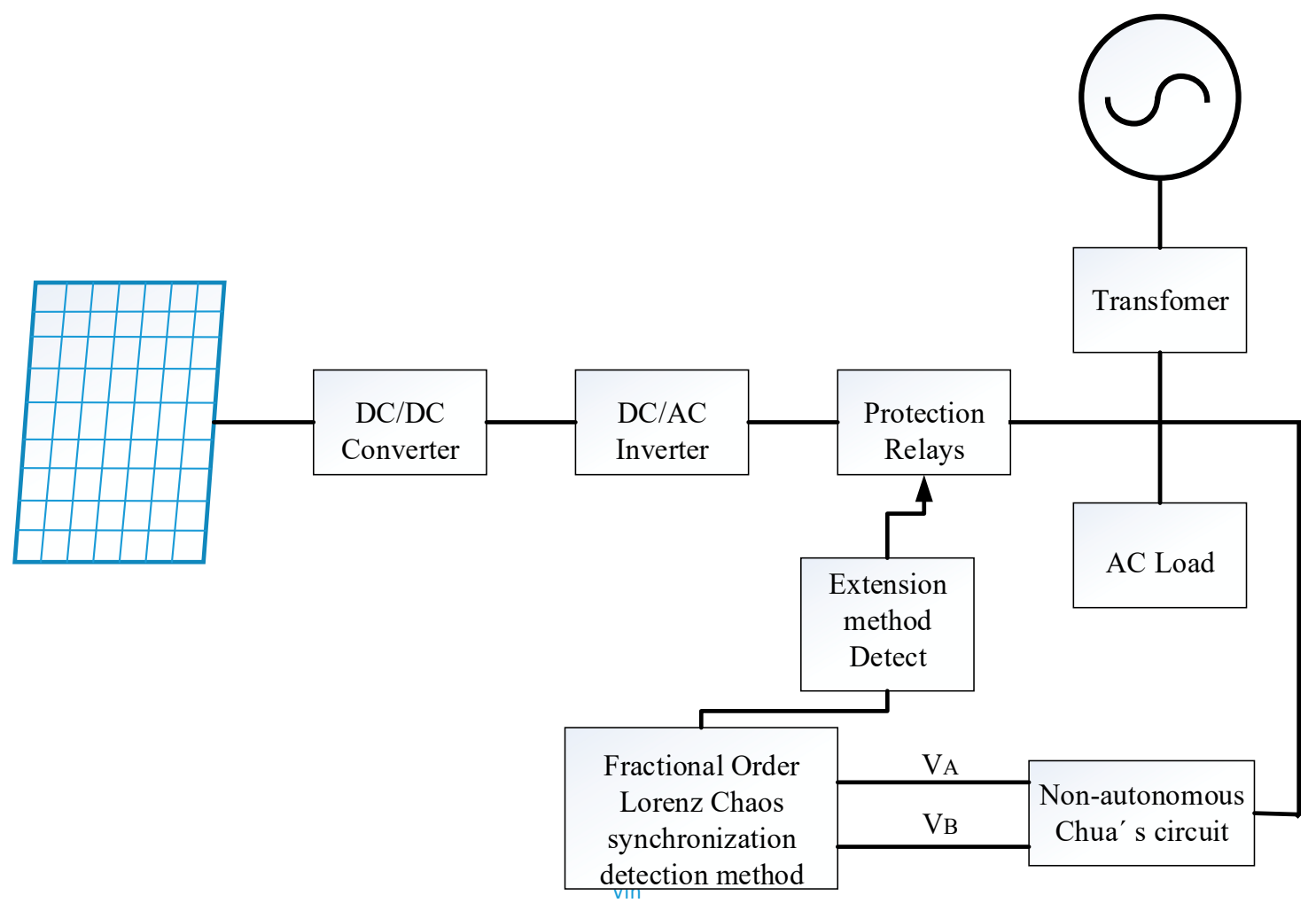

Figure 4. Grid-connected network using a Chua's non-autonomous circuit.

\section{Master and Slave Chaotic System}

The chaotic dynamic characteristics are frequently discussed in nonlinear systems theory [24]. The signals generated by a chaotic system can cause a signal to generate an ordered but aperiodic motion path under the influence of a chaotic attractor and, if such a motion path is subjected to tiny changes, these can have a much greater effect on the result. Chaotic signal self-synchronization can be regarded as being comprised of a Master System (MS) and a Slave System (SS). When the initial values of the two systems are different, the motion paths of each system will exhibit different chaotic behavior. However, synchronized action can be generated by adding a controller to the slave system to track the master system.

In this study, the characteristic extracted is the amount of naturally caused dynamic error of the MS and the SS in a synchronized system. Therefore, the master and slave synchronization system described here does not require the installation of a controller because the dynamic error state can be obtained from the difference between the MS and SS. Using the Lorenz system as an example, the dynamic equation is as expressed by Equations (3) and (4).

Master:

$$
\left\{\begin{array}{l}
\dot{x}_{1}=\alpha\left(x_{2}-x_{1}\right) \\
\dot{x}_{2}=\beta x_{1}-x_{1} x_{3}-x_{2} \\
\dot{x}_{3}=x_{1} x_{2}-\gamma x_{3}
\end{array}\right\}
$$

Slave:

$$
\left\{\begin{array}{l}
\dot{y}_{1}=\alpha\left(y_{2}-y_{1}\right) \\
\dot{y}_{2}=\beta y_{1}-y_{1} y_{3}-y_{2} \\
\dot{y}_{3}=y_{1} y_{2}-\gamma y_{3}
\end{array}\right\}
$$


The dynamic error is defined as $e_{1}=x_{1}-y_{1}, e_{2}=x_{2}-y_{2}$ and $e_{3}=x_{3}-y_{3}$. Therefore, the error dynamic vector is $e=\left[e_{1}, e_{2}, e_{3}\right]^{T}$ and the equation of the dynamic error state is expressed by Equation (5).

$$
\left[\begin{array}{c}
\dot{e}_{1} \\
\dot{e}_{2} \\
\dot{e}_{3}
\end{array}\right]=\left[\begin{array}{ccc}
-\alpha & \alpha & 0 \\
\beta & -1 & 0 \\
0 & 0 & -\gamma
\end{array}\right]\left[\begin{array}{l}
e_{1} \\
e_{2} \\
e_{3}
\end{array}\right]+\left[\begin{array}{c}
0 \\
-e_{1} e_{3} \\
e_{1} e_{2}
\end{array}\right]
$$

According to the similar fractional value [25] proposed by Grünwald-Letnikov, this can be expressed by Equation (6), which is shown below.

$$
D_{e}^{ \pm \alpha} e^{m} \approx \frac{\Gamma(m+1)}{\Gamma(m+1 \pm \alpha)} e^{m \pm \alpha}
$$

where $e$ is the dynamic error, $\mathrm{m}$ is any real number, and $\Gamma(\bullet)$ is the gamma function. By using the aforementioned equation to perform the fractional conversion on a fractional system (7), Equation (8) is obtained.

$$
\begin{gathered}
\frac{d}{d t} \frac{d^{-\alpha}}{d t^{-\alpha}} \approx A(e) \frac{d^{-\alpha}}{d t^{-\alpha}}\left[\begin{array}{l}
e_{1}^{1} \\
e_{2}^{1} \\
e_{3}^{1}
\end{array}\right]+\frac{d^{-\alpha}}{d t^{-\alpha}}\left[\begin{array}{c}
e_{1}^{0} \\
-e_{1} e_{3} \\
e_{1} e_{3}
\end{array}\right] \\
{\left[\begin{array}{c}
D^{q} e_{1} \\
D^{q} e_{2} \\
D^{q} e_{3}
\end{array}\right] \approx\left[\begin{array}{ccc}
-\alpha^{\prime} & \alpha^{\prime} & 0 \\
\beta^{\prime} & 0 & 0 \\
0 & 0 & -\gamma^{\prime}
\end{array}\right]\left[\begin{array}{c}
e_{1}^{1+\alpha} \\
e_{2}^{1+\alpha} \\
e_{3}^{1+\alpha}
\end{array}\right]+\left[\begin{array}{c}
\frac{\Gamma(1) e_{1}^{\alpha}}{\Gamma(1+\alpha)} \\
\frac{\Gamma(1) e_{1} e_{3} e_{2}^{\alpha}}{\Gamma(1+\alpha)} \\
\frac{\Gamma(1) e_{1} e_{2} e_{3}^{\alpha}}{\Gamma(1+\alpha)}
\end{array}\right]}
\end{gathered}
$$

where $q=(1-q), 0<q \leq 1$ is a fractional order between 0 and 1 , and $\Gamma(1)=\Gamma(2)=1$ wherein the system parameters of $\alpha^{\prime}, \beta^{\prime}$, and $\gamma^{\prime}$ are nonzero parameters after conversion. The relationship is expressed by Equation (9).

$$
\alpha^{\prime}=\frac{\alpha \Gamma(2)}{\Gamma(2+\alpha)}, \beta^{\prime}=\frac{\beta \Gamma(2)}{\Gamma(2+\alpha)}, \gamma^{\prime}=\frac{\gamma \Gamma(2)}{\Gamma(2+\alpha)}
$$

To establish a self-synchronizing error system, the equation of the dynamic error is below.

$$
e_{1}[i]=x_{1}[i]-y_{1}[i], e_{2}[i+1]=x_{2}[i+1]-y_{2}[i], e_{3}[i]=x_{3}[i+2]-y_{3}[i+2]
$$

Therefore, the dynamic equation of the self-synchronizing error system can be defined by Equation (10) below.

$$
\left[\begin{array}{l}
\Phi_{1}[i] \\
\Phi_{2}[i] \\
\Phi_{3}[i]
\end{array}\right] \approx\left[\begin{array}{ccc}
-\alpha^{\prime} & \alpha^{\prime} & 0 \\
\beta^{\prime} & 0 & 0 \\
0 & 0 & -\gamma^{\prime}
\end{array}\right]\left[\begin{array}{l}
e_{1}[i]^{1+\alpha} \\
e_{2}[i]^{1+\alpha} \\
e_{3}[i]^{1+\alpha}
\end{array}\right]+\left[\begin{array}{c}
\frac{\Gamma(1) e_{1}[]^{\alpha}}{\Gamma(1+\alpha)} \\
\frac{\Gamma(1) e_{1}[i] e_{3}[i] e_{2}[i]^{\alpha}}{\Gamma(1+\alpha)} \\
\frac{\Gamma(1) e_{1}[i] e_{2}[i] e_{3}[i]^{\alpha}}{\Gamma(1+\alpha)}
\end{array}\right]
$$

The preprocessed $V_{A}$ and $V_{B}$ voltages from the Chua's circuit are used as the signals to be added to the MS and SS and yield chaotic fractional self-synchronization dynamic error signals between the two systems. Finally, using the dynamic errors $e_{2}, e_{3}$ phase plane paths, an extension theory element model is constructed and used to determination the presence of islanding in the output signal of the monitored system. Figure 5 is a diagram of the system flow chart. 


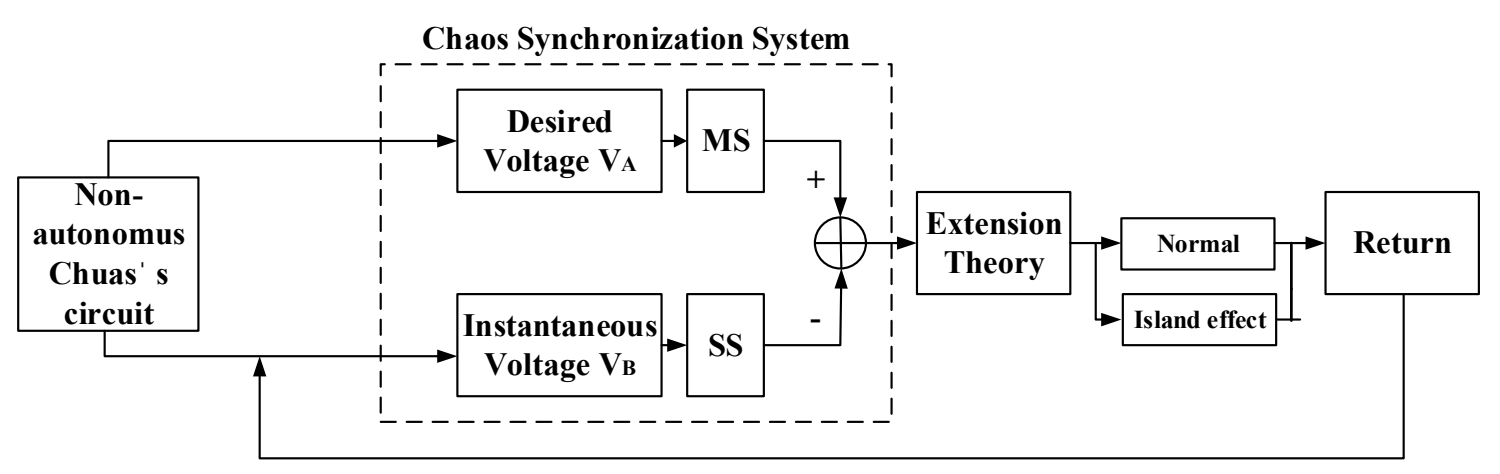

Figure 5. Flow chart of the islanding diagnosis system.

\section{Extension Theory}

The extension theory [26] was proposed by Professor Wen Tsai in 1983 to handle the paradox issue among objects and events such that by using its extensibility, the regularity among states can be found, and the mathematical computation method can be used to perform characteristic categorization. The extension theory has two cores including the element theory and the extension set. The element theory is used to study the property of element conversion to use it to solve the paradox issue. The extension set uses an extension model to solve the paradox issue and cannot be explained by traditional or fuzzy mathematics. The traditional logic only has 0 and 1 . The fuzzy set range is extended from $[0,1]$ and the extension theorem extended the region from $[0,1]$ to $[-1,1]$. The fuzzy set and the extension set are shown in Figure 6 [27]. Please refer to references $[28,29]$ for introductions to element theory and the extension set.

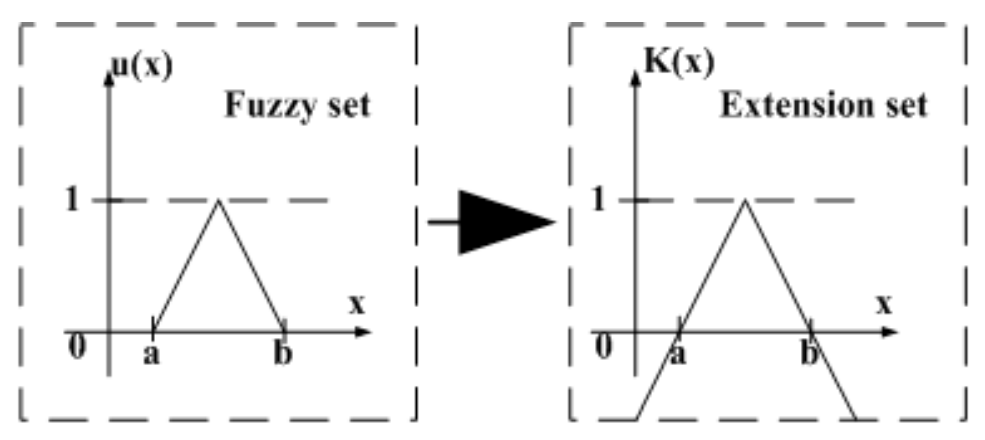

Figure 6. The fuzzy and extension sets.

In this study, the extension theory was used for fractional Lorenz chaotic system backend detection. The extension theory has the advantage that the closer the element to be measured is to the classic domain, the greater the correlation function. The degree of correlation will reveal the presence of islanding in a simple evaluation of objects with a high level of compliance.

\section{Simulation Results}

MATLAB (2015) was used to simulate the grid-connected solar power generation system used as the basis of this study (see Figure 7). Figure 8 shows the waveforms when the solar power system has been disconnected from the grid. 


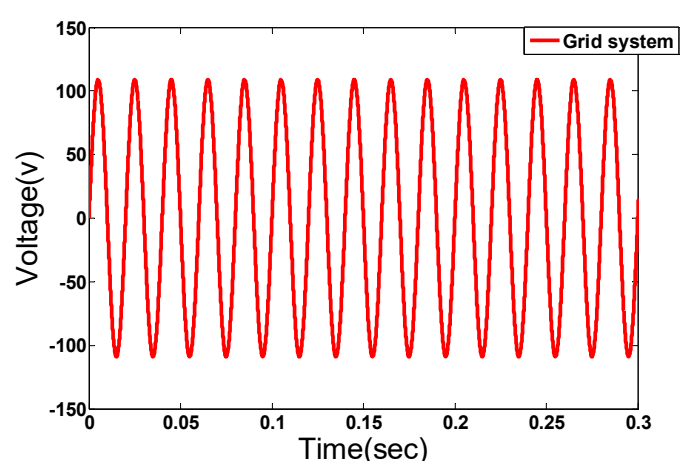

(a)

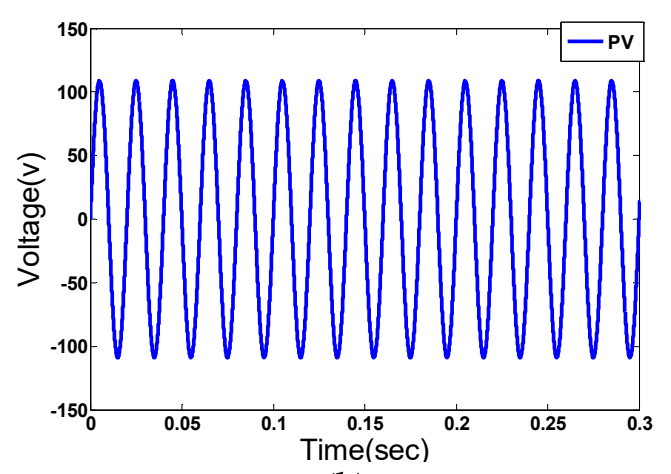

(b)

Figure 7. (a,b) Waveforms of generated solar power connected to the grid.

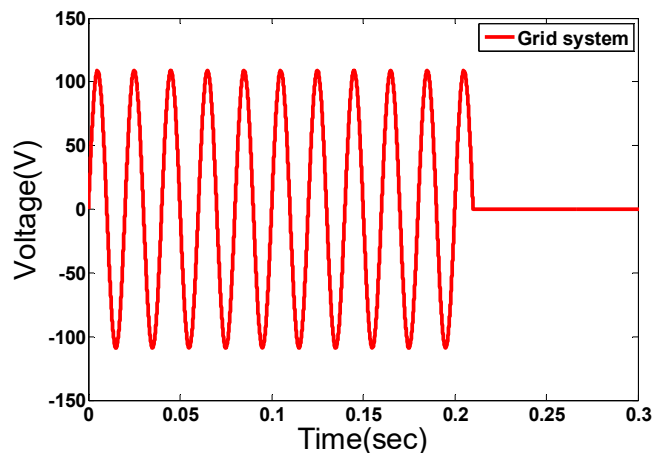

(a)

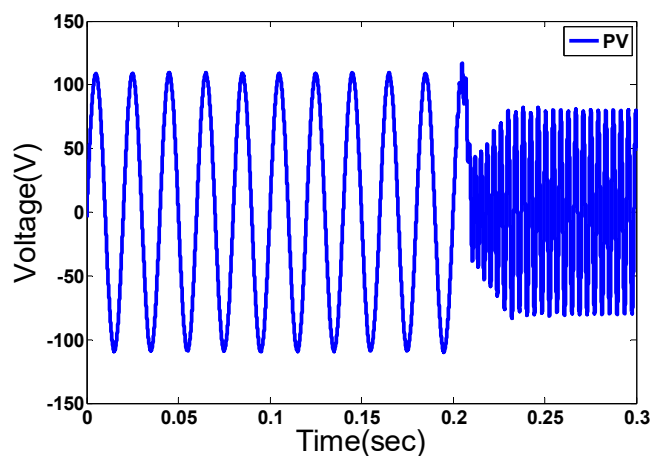

(b)

Figure 8. (a,b) Waveforms of generated solar power disconnected from the grid.

In this study, the chaotic characteristic is utilized in such a way that, when islanding occurs, the tiny vibrations generated can be observed as chaotic self-synchronized dynamic error waveforms. This study uses an example where the nonlinear Chua's circuit is utilized to capture voltages $\mathrm{V}_{\mathrm{A}}$ and $V_{B}$. Then the dynamic error equations of the fractional Lorenz chaotic system are used to convert the $\mathrm{V}_{\mathrm{A}}$ and $\mathrm{V}_{\mathrm{B}}$ electric waveforms from the Chua's circuit by using the master and slave chaotic system. The resulting dynamic error value is then extracted to be used as the characteristic for the extension identification method. The dynamic error path graphs for changes from $\alpha=1$ to $\alpha=0.1$ are shown in Figure 9 (no islanding) and Figure 10 (showing islanding).

It can be seen, from the dynamic path graphs, that when $\alpha=1$ is a normal integral, the value of the dynamic error is relatively large. This makes it difficult to determine whether islanding has occurred because the dynamic error distribution points show no significant difference and the backend use of the extension theory to detect islanding would be problematic. However, an examination of Figures 9 and 10 clearly shows that the differences between the graphs of the chaotic paths under different fractional orders is quite easy to see and islanding is obvious in many cases. After comparing the waveform graphs in the figures and giving consideration to the form and the center of gravity, the order with the greatest differences was selected. In this study, the order with the greatest differences was 0.6 and was set between the $-2 \sim 0$ interval and $0 \sim 6$ interval while the value was the characteristic value extracted in this study. The center of gravity was located on the dynamic error phase plane graph to extract a characteristic value. The red dot is at the center of gravity of the chaotic characteristic waveform to emphasize the determination intensity. Table 1 refers to an element model for determining whether islanding will occur. Finally, using the constructed element model with the weight of each element set at 0.25 , extension identification can be used for signal detection and the accurate determination of the presence of islanding. 


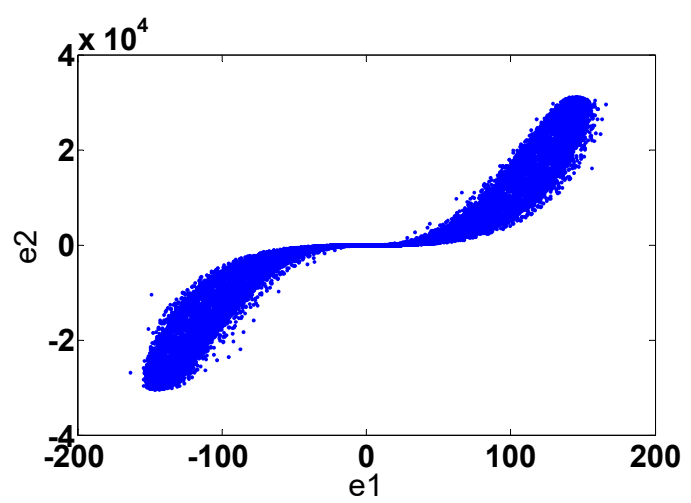

(a)

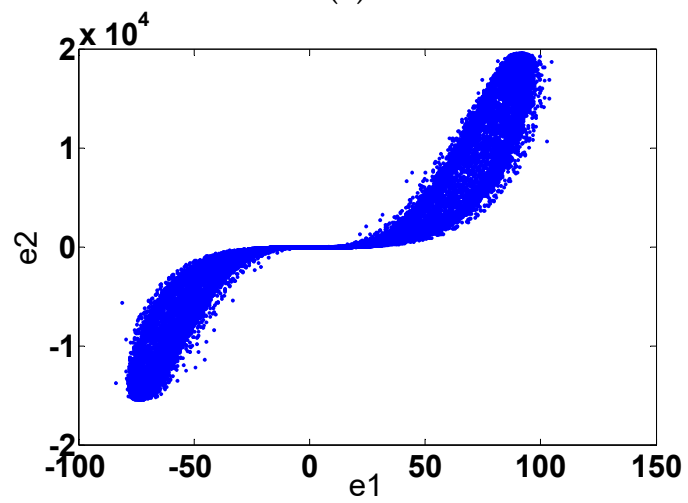

(c)

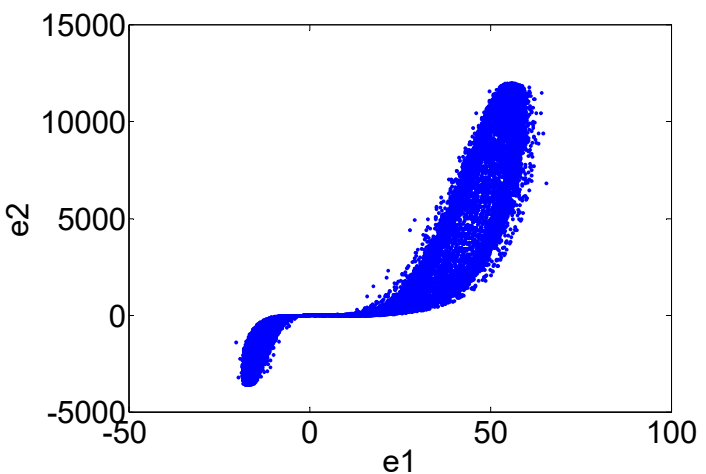

(e)

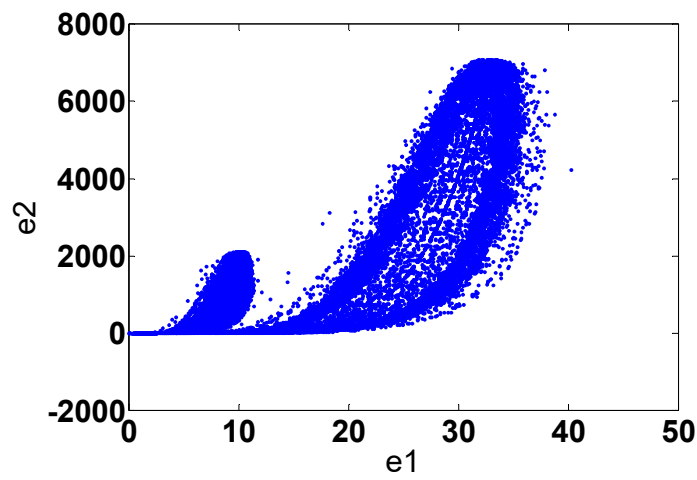

(g)

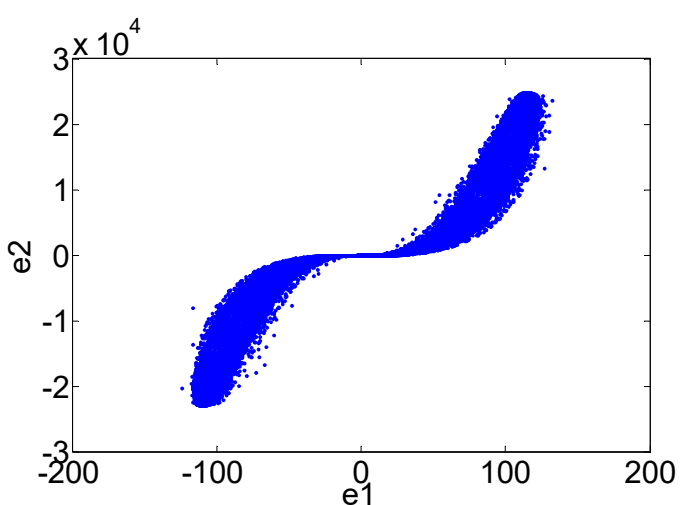

(b)

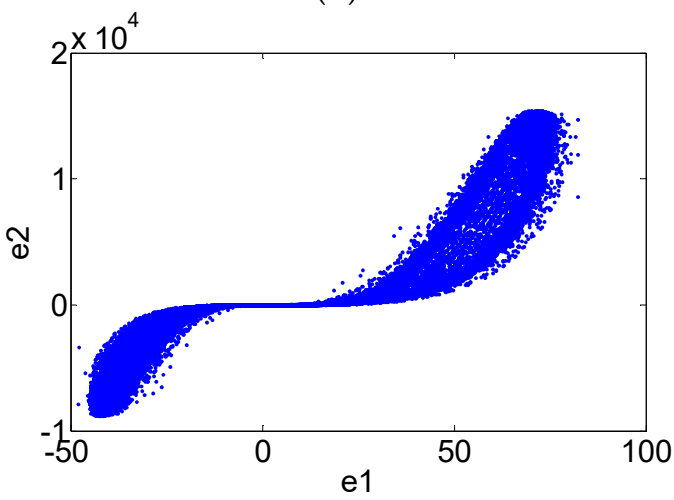

(d)

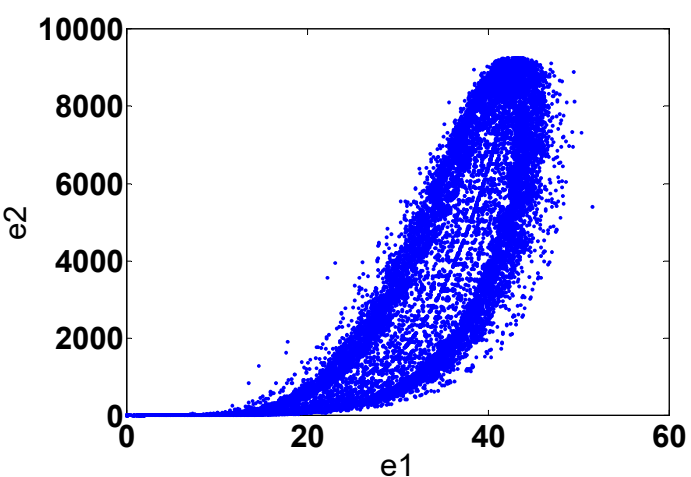

(f)

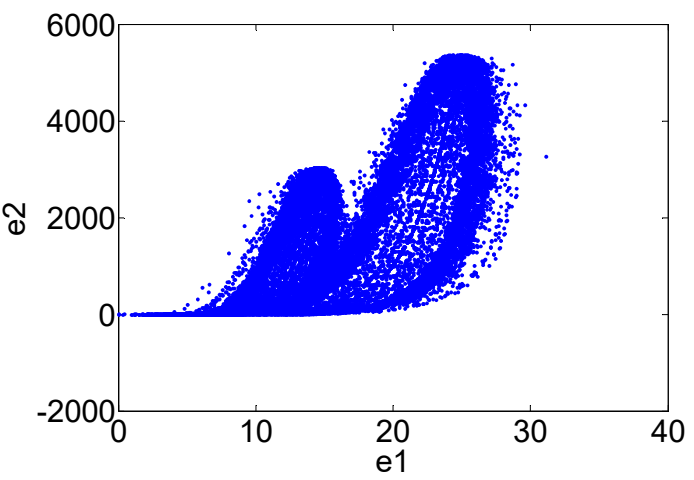

(h)

Figure 9. Cont. 


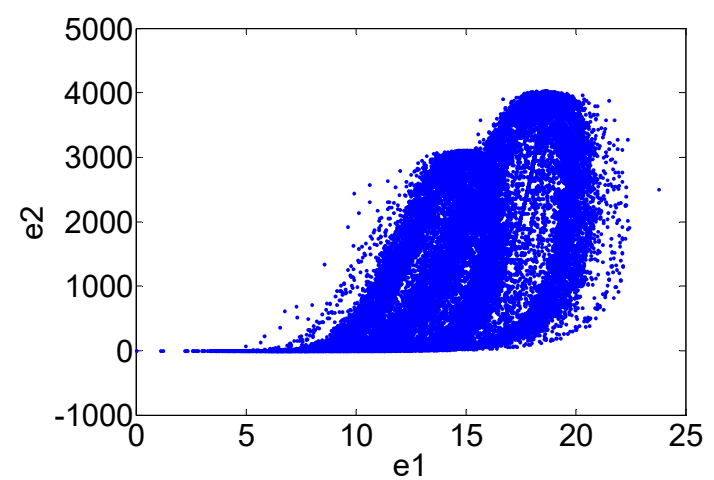

(i)

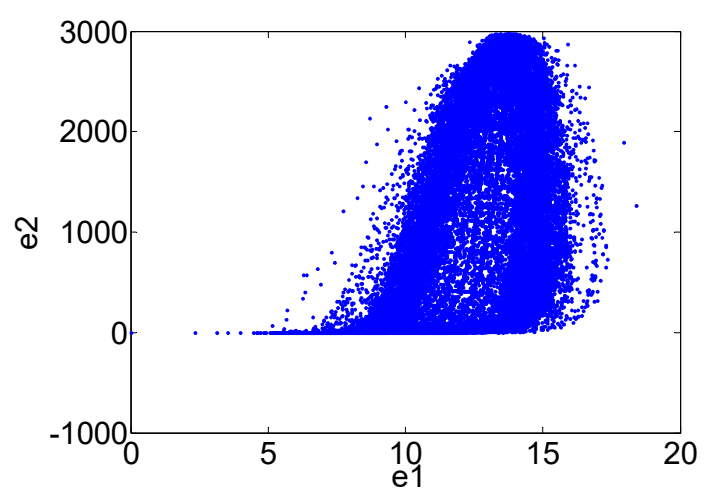

(j)

Figure 9. Chaotic dynamic error path showing no islanding. (a) $\alpha=1$ (b) $\alpha=0.9$ (c) $\alpha=0.8$ (d) $\alpha=0.7$ (e) $\alpha=0.6(\mathbf{f}) \alpha=0.5(\mathbf{g}) \alpha=0.4(\mathbf{h}) \alpha=0.3(\mathbf{i}) \alpha=0.2(\mathbf{j}) \alpha=0.1$.

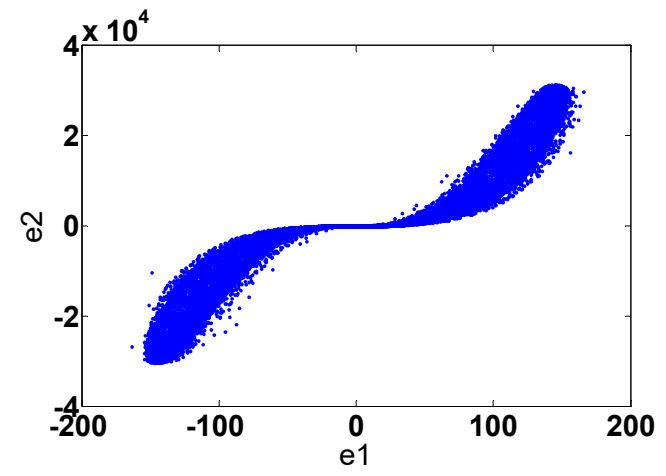

(a)

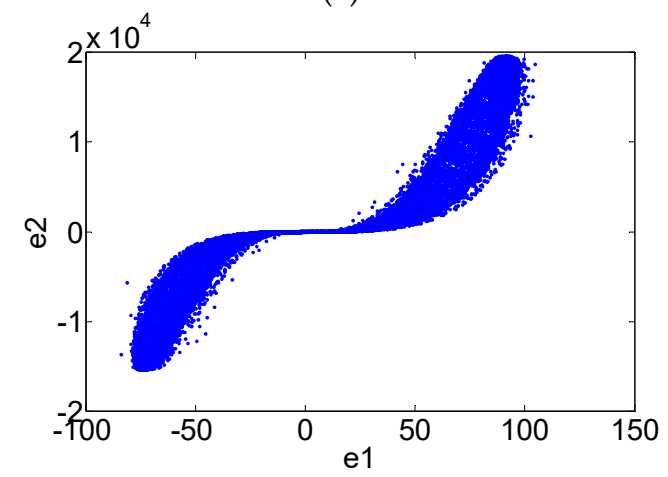

(c)

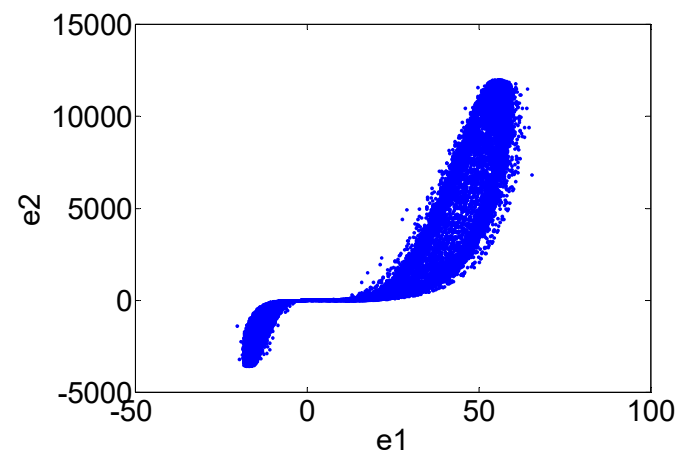

(e)

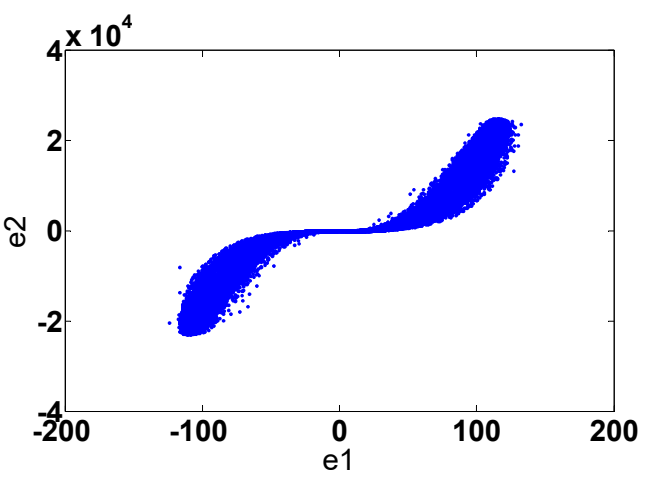

(b)

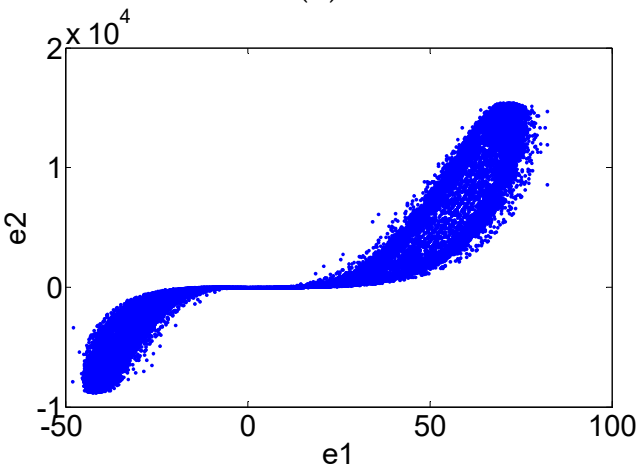

(d)

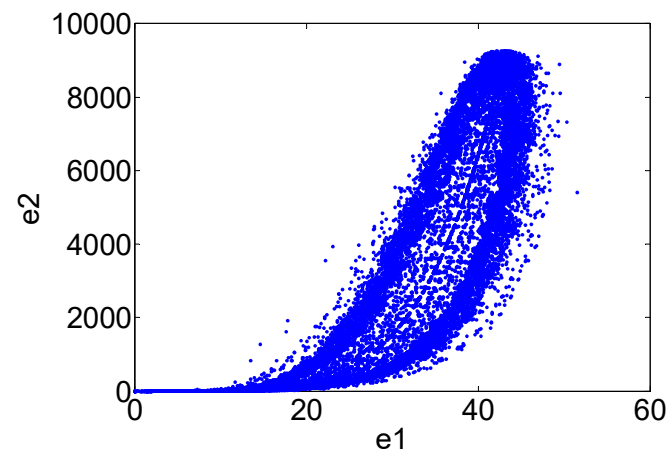

(f)

Figure 10. Cont. 


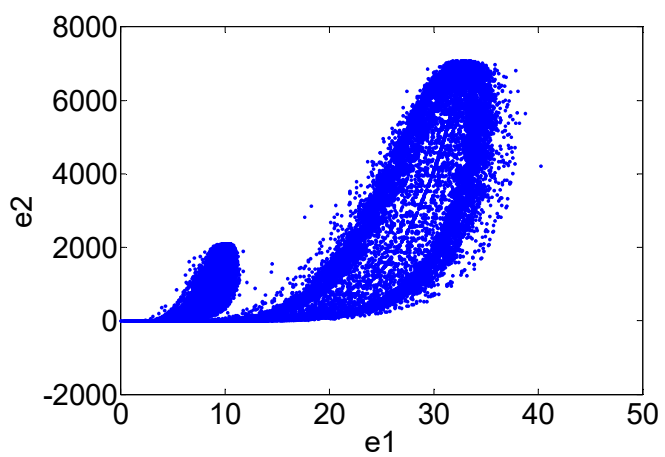

$(\mathrm{g})$

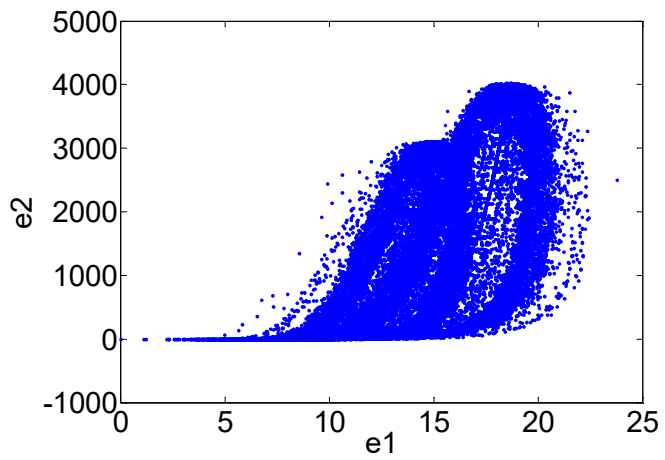

(i)

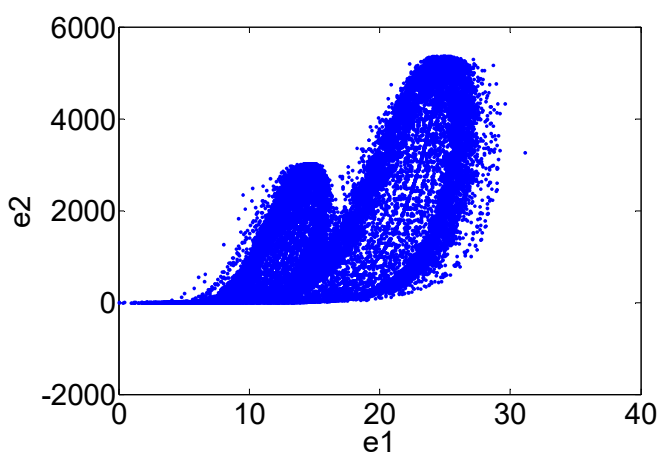

(h)

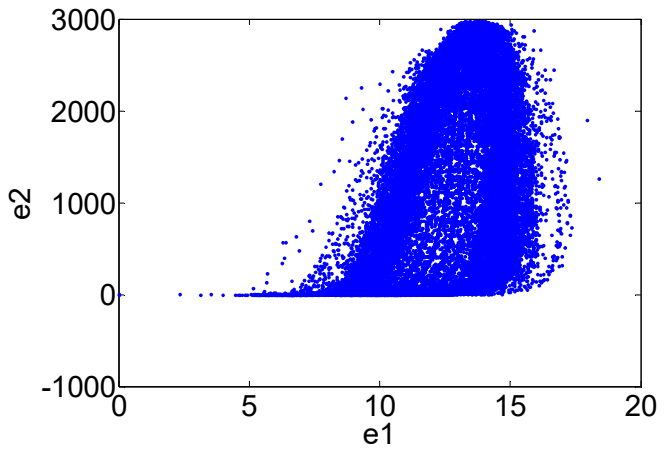

$(\mathbf{j})$

Figure 10. Chaotic dynamic error path showing islanding. (a) $\alpha=1$ (b) $\alpha=0.9$ (c) $\alpha=0.8$ (d) $\alpha=0.7$ (e) $\alpha=0.6$ (f) $\alpha=0.5$ (g) $\alpha=0.4$ (h) $\alpha=0.3$ (i) $\alpha=0.2(\mathbf{j}) \alpha=0.1$.

To simulate the condition of real-time monitoring, the signal to be detected is shown in Figure 11 where the power grid is disconnected at different times to cause the islanding or the load is changed before disconnection. The signals are then detected using the fractional Lorenz chaotic extension detection method. The value 1 , in the correlation value of the extension theory, refers to the detection result and Table 2 shows the real-time results for determining islanding. Ten records were selected from 100 samples.
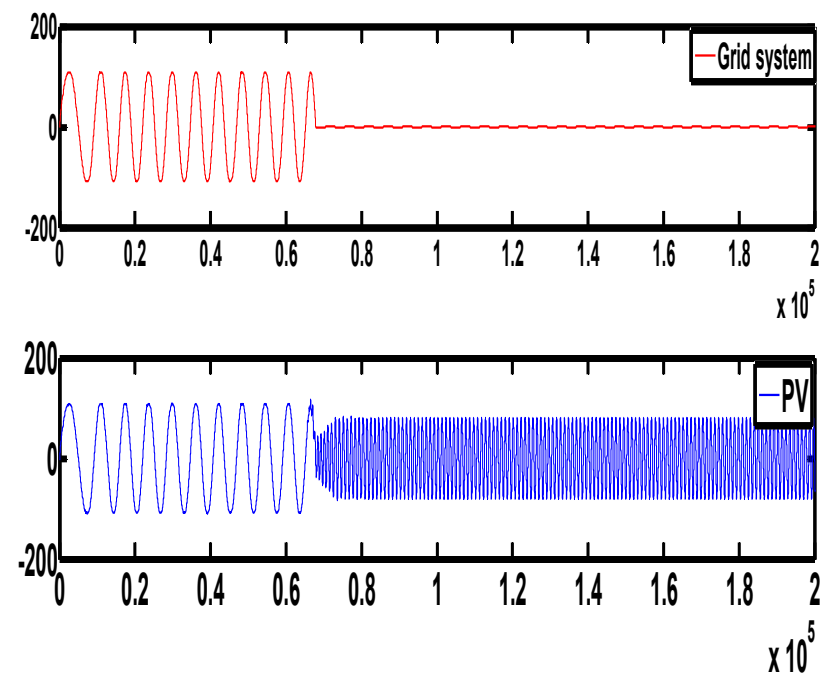

Figure 11. Monitored waveforms of detected signals. 
Table 1. Extension element model showing when islanding will occur.

$\left[\begin{array}{ccc}\text { Normal } & C_{1} & {[0,-500]} \\ & C_{2} & {[1000,1200]} \\ & C_{3} & {[50,80]} \\ & C_{4} & {[1,1.7]}\end{array}\right] \quad\left[\begin{array}{ccc}\text { Island } & C_{1} & {[0,-500]} \\ & C_{2} & {[1100,1500]} \\ & C_{3} & {[40,60]} \\ & C_{4} & {[1.5,2]}\end{array}\right]$

Table 2. Real-time monitored results (correlation).

\begin{tabular}{ccccc}
\hline Sample & Normal & Islanding & Actual Category & Detection Category \\
\hline 1 & -1 & 1 & Islanding & Islanding \\
2 & 1 & -1 & Normal & Normal \\
3 & -1 & 1 & Islanding & Islanding \\
4 & -1 & 1 & Islanding & Islanding \\
5 & -1 & 1 & Islanding & Islanding \\
6 & 1 & -1 & Normal & Normal \\
7 & 1 & -1 & Normal & Normal \\
8 & -1 & 1 & Islanding & Islanding \\
9 & -1 & 1 & Islanding & Islanding \\
10 & -1 & 1 & Islanding & Islanding \\
\hline
\end{tabular}

Table 2 shows that, in a simulation of real-time monitoring, the accuracy of the fractional Lorenz chaotic extension detection method for islanding is $100 \%$. Simulations of the intelligent algorithms of other studies as well as traditional detection methods were made as comparisons. The results are shown in Figure 12. It is clear that the Lorenz method is the most accurate and can be of practical use.

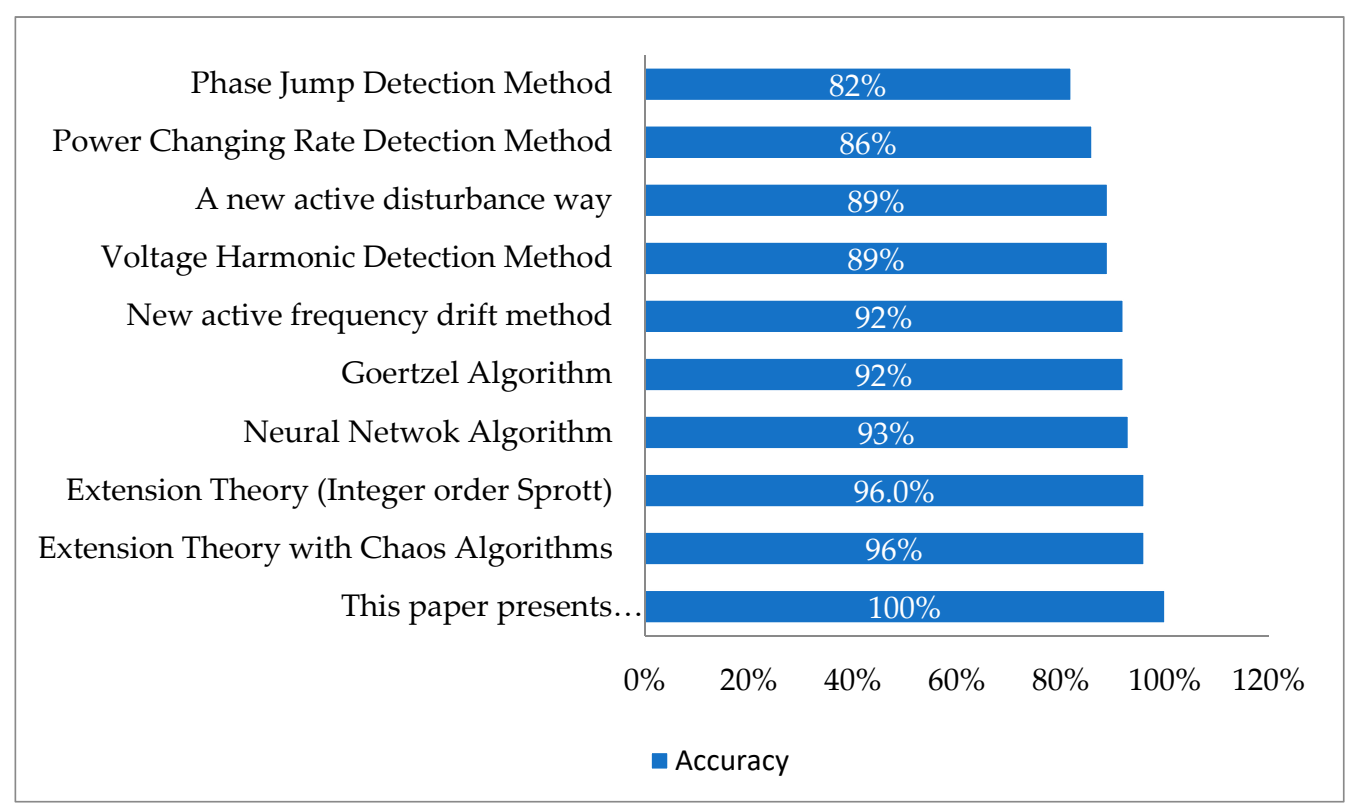

Figure 12. Accuracy comparisons between traditional methods and the method proposed in this paper.

\section{Conclusions}

In this study a new instant detection method has been presented that uses an extension of Fractional Order Lorenz Chaos Synchronization. By including $\mathrm{V}_{\mathrm{A}}$ and $\mathrm{V}_{\mathrm{B}}$ from a Chua's circuit in a master-slave chaotic system to detect dynamic errors, a matter-element model was created to extract visible Eigen values for extension identification. Matlab was used to simulate a parallel connection between city power and a solar power generation system. Since the orders of the dynamic chart 
can be chosen when compared with other methods [14] reduces the difficulty of matter-element model design and allows rapid detection of islanding. In the simulations, the accuracy rate for instantaneous detection reached $100 \%$. A practical and intelligent human machine interface for monitoring a parallel connection between solar and city power can easily be set up using LabVIEW. In this study, the combination of a non-volitional Chua's circuit with chaotic extension was used. The architecture is simple, easy to accomplish, and is fast and accurate. For this method, only the voltage needs to be retrieved while the other more traditional methods require voltage, frequency, phase data, and more. Such a system is very simple and inexpensive and could easily be included in the original setup of a solar power mains electricity combination. A user would be able to quickly and accurately detect islanding and take action to avoid problems. This would facilitate maintenance and also help to ensure the safety of maintenance staff.

Furthermore, the system can be used to record and save captured signals and diagnosis. If EtherCAT were combined with this system, information could be uploaded to the cloud where it would be available to others users. The cloud data can also be integrated with the system to give warnings about trouble spots.

Author Contributions: All the authors took part in this research project. Conceptualization, H.-T.Y. and C.-B.F.; Software, C.-B.F.; Validation, A.-H.T.; Investigation, Y.-C.L.; Writing-Original Draft Preparation, A.-H.T.; Writing-Review \& Editing, H.-T.Y. and Y.-C.L.

Acknowledgments: The authors would like to thank the Ministry of Science and Technology, Taiwan, for financial support of this project under Contract No. MOST 104-2221-E-167-001 and MOST104-2622-E-167-019-CC3. We also would like to thank the financial support of Yunnan Science and Technology Department and Education Department Project (2017FH001-067,2017FH001-117,2016ZDX127), China.

Conflicts of Interest: The authors declare no conflict of interest.

\section{References}

1. Wang, M.-H.; Yau, H.-T. New Power Quality Analysis Method Based on Chaos Synchronization and Extension Neural Network. Energies 2014, 7, 6340-6357. [CrossRef]

2. Chicco, G.; Cocina, V.; Di Leo, P.; Spertino, F; Massi Pavan, A. Error Assessment of Solar Irradiance Forecasts and AC Power from Energy Conversion Model in Grid-Connected Photovoltaic Systems. Energies 2016, 9, 8. [CrossRef]

3. Han, J.; Lee, I.; Kim, S.H. User-friendly monitoring system for residential PV system based on low-cost power line communication. IEEE Trans. Consum. Electron. 2015, 61, 175-180. [CrossRef]

4. Paliwal, P.; Patidar, N.P.; Nema, R.K. A comprehensive survey of optimization techniques used for Distributed Generator siting and sizing. In Proceedings of the 2012 IEEE Southeastcon, Orlando, FL, USA, 15-18 March 2012; pp. 1-7.

5. Song, I.-K.; Jung, W.-W.; Chu, C.-M.; Cho, S.-S.; Kang, H.-K.; Choi, J.-H. General and Simple Decision Method for DG Penetration Level in View of Voltage Regulation at Distribution Substation Transformers. Energies 2013, 6, 4786. [CrossRef]

6. Laaksonen, H. Advanced Islanding Detection Functionality for Future Electricity Distribution Networks; IEEE Power \& Energy Society: Piscataway, NJ, USA, 2013; Volume 28, pp. 2056-2064.

7. Zhang, R.; Zhang, S.; Wang, P.; Liu, X. A new active island detection method which is based on a novel disturbance way. In Proceedings of the 2014 9th IEEE Conference on Industrial Electronics and Applications, Hangzhou, China, 9-11 June 2014; pp. 1214-1220.

8. Zhang, C.-J.; Wang, X.; Meng, H.-Y.; Zhang, X.-B.; Xu, D.-G. A new adaptive active frequency drift method for islanding detection of grid-connected inverters. In Proceedings of the 2008 International Conference on Electrical Machines and Systems, Wuhan, China, 17-20 October 2008; pp. 2742-2745.

9. Bitaraf, H.; Sheikholeslamzadeh, M.; Ranjbar, A.M.; Mozafari, B. Neuro-fuzzy islanding detection in distributed generation. In Proceedings of the IEEE PES Innovative Smart Grid Technologies, Tianjin, China, 21-24 May 2012; pp. 1-5.

10. Meher, S.K.; Pradhan, A.K. Fuzzy classifiers for power quality events analysis. Electr. Power Syst. Res. 2010, 80, 71-76. [CrossRef] 
11. Guo, P.; Wang, X.; Han, Y. The enhanced genetic algorithms for the optimization design. In Proceedings of the 2010 3rd International Conference on Biomedical Engineering and Informatics, Yantai, China, 16-18 October 2010; pp. 2990-2994.

12. Kim, J.H.; Kim, J.G.; Ji, Y.H.; Jung, Y.C.; Won, C.Y. An Islanding Detection Method for a Grid-Connected System Based on the Goertzel Algorithm. IEEE Trans. Power Electron. 2011, 26, 1049-1055. [CrossRef]

13. Soo-Chang, P.; Min-Hung, Y.; Tzyy-Liang, L. Fractional Fourier series expansion for finite signals and dual extension to discrete-time fractional Fourier transform. IEEE Trans. Signal Process. 1999, 47, 2883-2888. [CrossRef]

14. Wang, M.H.; Huang, M.L.; Liou, K.J. Islanding detection method for grid connected photovoltaic systems. IET Renew. Power Gener. 2015, 9, 700-709. [CrossRef]

15. Jha, A.G.; Das, A.P.; Abhinav, K. Effects of electromagnetic interference on non-autonomous chaotic circuits. In Proceedings of the 2009 4th International Conference on Computers and Devices for Communication (CODEC), Kolkata, India, 14-16 December 2009; pp. 1-4.

16. Ginarsa, I.M.; Soeprijanto, A.; Purnomo, M.H. Controlling chaos and voltage collapse using an ANFIS-based composite controller-static var compensator in power systems. Intern. J. Electr. Power Energy Syst. 2013, 46, 79-88. [CrossRef]

17. Precup, R.-E.; Tomescu, M.-L.; Dragos, C.-A. Stabilization of Rössler chaotic dynamical system using fuzzy logic control algorithm. Int. J. Gen. Syst. 2014, 43, 413-433. [CrossRef]

18. Choudhary, S.K. LQR based optimal control of chaotic dynamical systems. Int. J. Model. Simul. 2015, 35, 104-112. [CrossRef]

19. Bouzeriba, A.; Boulkroune, A.; Bouden, T. Projective synchronization of two different fractional-order chaotic systems via adaptive fuzzy control. Neural Comput. Appl. 2016, 27, 1349-1360. [CrossRef]

20. Su, H.; Zhao, F. Chaos Detection Method for Power Quality Disturbance. In The Sixth World Congress on Intelligent Control and Automation 2006; IEEE: Piscataway, NJ, USA, 2006; Volume 1.

21. Ropp, M.; Ellis, A. Suggested Guidelines for Anti-Islanding Screening; Technical Report SAND2012-1365; Sandia National Laboratories: Albuquerque, NM, USA, February 2012.

22. Pinto, R.; Mariano, S.; Calado, M.; de Souza, J. Impact of Rural Grid-Connected Photovoltaic Generation Systems on Power Quality. Energies 2016, 9, 739. [CrossRef]

23. Lopes, J.A.P.; Moreira, C.L.; Madureira, A.G. Defining control strategies for MicroGrids islanded operation. IEEE Trans. Power Syst. 2006, 21, 916-924. [CrossRef]

24. Huang, C.H.; Lin, C.H.; Kuo, C.L. Chaos Synchronization-Based Detector for Power-Quality Disturbances Classification in a Power System. IEEE Trans. Power Deliv. 2011, 26, 944-953. [CrossRef]

25. Rekanos, I.T.; Yioultsis, T.V. Approximation of Grünwald-Letnikov Fractional Derivative for FDTD Modeling of Cole-Cole Media. IEEE Trans. Magn. 2014, 50, 181-184. [CrossRef]

26. Wang, M.H.; Tsai, H.H. Fuel cell fault forecasting system using grey and extension theories. IET Renew. Power Gener. 2012, 6, 373-380. [CrossRef]

27. Wang, M.H. Application of extension theory to vibration fault diagnosis of generator sets. In IEE ProceedingsGeneration, Transmission and Distribution; IET: Michael Faraday House, Stevenage, 2004; Volume 151, pp. 503-508.

28. Mang-Hui, W.; Chih-Yung, H. Application of extension theory to PD pattern recognition in high-voltage current transformers. IEEE Trans. Power Deliv. 2005, 20, 1939-1946.

29. Mang-Hui, W. Extension neural network-type 2 and its applications. IEEE Trans. Neural Netw. 2005, 16, 1352-1361.

(C) 2018 by the authors. Licensee MDPI, Basel, Switzerland. This article is an open access article distributed under the terms and conditions of the Creative Commons Attribution (CC BY) license (http://creativecommons.org/licenses/by/4.0/). 